\author{
Hatice ALTINOK, PhD Candidate \\ E-mail: haltinok@anadolu.edu.tr \\ Professor Mehmet Oğuz ARSLAN, PhD \\ E-mail: moarslan@anadolu.edu.tr \\ Department of Public Finance \\ Faculty of Economics and Administrative Sciences \\ Anadolu University
}

\title{
THE RELATIONSHIP BETWEEN PUBLIC EXPENDITURES AND ECONOMIC GROWTH IN SOUTHEASTERN EUROPEAN COUNTRIES: AN ANALYSIS OF BOOTSTRAP PANEL GRANGER CAUSALITY
}

\begin{abstract}
Wagner's Law is a model which explains an increase in public expenditures. In this study, we test the existence of the Granger causality between public expenditures and economic growth of Southeastern European countries (Albania, Bosnia Herzegovina, Bulgaria, Croatia, Greece, North Macedonia, Montenegro, Romania, Serbia, Slovenia, and Turkey) using an advanced econometric technique which is not used in previous empirical studies by using annual panel time series data throughout for 2002-2017. The results of the study provide mix evidence about the directions and the signs of the causality in those countries. An increase in real GDP causes an increase in public expenditures in most of the Southeastern European countries. On the other side, an increase in public expenditures causes an increase in real GDP for some Southeastern countries and also causes a decrease in real GDP for others. In this paper, we have found bi-directional causality for most of those countries. Also, the results of the study indicate that the sign of the relationship between real GDP and public expenditures differs by countries. Finally, we have reached two opposite conclusions on the validity of Wagner's Law for Southeastern European countries in this study, using Kónya test.
\end{abstract}

Keywords: Wagner's law, public expenditures, Bootstrap panel causality.

\section{JEL Classification : H50, C10, C31}

\section{Introduction}

The relationship between public expenditures and economic growth has been investigated since the 19th century. Since then, some economists assert the share of the government has been impairing productivity and economic growth even though some economists stress the importance of the role of government for economic

DOI: $10.24818 / 18423264 / 54.3 .20 .15$ 
Hatice Altinok, Mehmet Oğuz Arslan

growth. Today, it is a known fact that the policies of public expenditures have great importance in all economies. There are two approaches in order to explain the relation between public expenditures and economic growth. The first approach is Wagner's Law that accepts economic growth as the main reason for an increase in public expenditures. The second approach is the Keynesian approach that accepts vice versa.

In his study in 1883, Wagner concluded that the economic activity of governments increases in the time course of economic growth. Wagner analyzed the economies of Great Britain, North American countries, Switzerland, and Prussia and pointed out that the public expenditures had increased as a result of the increase in economic growth in those countries. According to Wagner, the main factors for the increase in the public expenditures are; technological progress, migration from the country to town and urbanization, the industrialization period (Wagner, 1883). This approach is named as "Wagner's Law (Hypothesis)" in economic literature.

According to Keynesian hypothesis, public expenditures is a tool of fiscal policy and a variable that affects economic growth. This approach accepts that the direction of causality is from public expenditures to economic growth.

In this paper, we test the validity of Wagner's Law for the economies of Albania, Bosnia and Herzegovina, Bulgaria, Croatia, Greece, North Macedonia, Montenegro, Romania, Serbia, Slovenia, and Turkey by using Kónya (2006) bootstrap causality test that is not used in previous empirical studies. Unlike other causality tests in literature, this test has some advantages. The first advantage is that we can determine the direction of the causality relationship between variables by using the Wald test in the model. The second and important advantage is that we can also determine the coefficient of the independent variable (the slope coefficient) in the model. Thus, we can interpret how much public expenditures will increase or decrease when economic growth is increased or decreased by one unit.

This paper consists of five main parts. The first part analyses related literature. The third part introduces the data set and the model. The fourth part gives methodological details of the analysis. The fifth part discusses the empirical findings of the econometric analysis. The last part concludes the study.

\section{RelatedLiterature}

From past to present many studies have investigated bi-direction or unidirectional causality relationship between GDP and public expenditures. Two main theories explain this relationship between these two variables. The first one is Wagner's law which has received support from many researchers by using both time-series and cross-sectional data sets and the second one is the Keynesian

DOI: $10.24818 / 18423264 / 54.3 .20 .15$ 
The Relationship between Public Expenditures and Economic Growth in Southeastern European Countries: An Analysis of Bootstrap Panel Granger Causality

hypothesis. Recently, some researchers analyzed both Wagner's Law and the Keynesian hypothesis.

Mann (1980) has analyzed six different versions of Wagner's Law using data for Mexico throughout 1925-1976. Mann (1980) has concluded that Wagner's Law is valid in three of six versions. Chletsos and Kollias (1997) have also tested Wagner's Law by using disaggregated public expenditures data for Greece using data from 1958 and 1993. Chletsos and Kollias (1997) have asserted that defense expenditures can be explained with Wagner's Law. On the other side, some studies have not supported Wagner's Law. For example, Guseh (1997) has investigated the validity of Wagner's Law for developing countries over the period 1960-1985. Guseh (1997) has put out that the growth in public expenditures has adverse effects on economic growth. Also, Tanninen (1999) has found that government expenditures have negative effects on economic growth. Islam (2001) has examined this approach for the USA throughout 1929-1996 and has concluded that Wagner's Law is valid in the USA. Halıcıoglu (2003) has analyzed both Wagner's Law and an augmented version of Wagner's Law over the period 1960-2000 for Turkey. Halıcioğlu (2003) has concluded that Wagner's Law is not valid but, an augmented version of Wagner's Law is valid for Turkey. Narayan, Nielse, and Smyth (2008) have investigated Wagner's Law for China. They have concluded that this approach is valid for central and western regions of China, although it is not valid for the eastern region of China. Jaen-Garcia (2011) has confirmed that the growth in output causes an increase in public expenditures for Spain's economy over the period 1984-2003. According to the study, the correlation between public expenditures and GDP per capita is positive. It means that Wagner's Law has been verified. Kuckuck (2012) has applied Wagner's Law for five industrialized European countries (the United Kingdom, Denmark, Sweden, Finland, and Italy) using data from 1850 to 1995 and has observed that the relationship between those variables has weakly supported Wagner's Law. Afonso and Alves (2016) have reconsidered Wagner's Law through the functions of public expenditures by using data of 14 European countries between 1966 and 2013 by using panel data and SUR methods. They have found that some evidence from a few European countries confirm Wagner's law. In addition to these studies, many researchers have investigated the relationship between public expenditures and economic growth.

Dritsakis and Adamopoulos (2004) have analyzed both Wagner's Law and the Keynesian hypothesis for the Greek economy for the 1960-2001 period using the Granger causality test. They have used three alternative models to analyze these hypothesizes. Both hypothesizes have supported bi-directional relationships between two variables for Greece. Magazzino (2010) has investigated an augmented version of Wagner's Law for the period of 1970-2009 for 27 EU countries by using Granger causality. The augmented version of Wagner's Law

DOI: $10.24818 / 18423264 / 54.3 .20 .15$ 
Hatice Altinok, Mehmet Oğuz Arslan

includes a long term relationship amongst public expenditures on one side and aggregate income and public deficit on the other. He has found that Wagner's law is valid for developing countries although the Keynesian hypothesis is not supported. Magazzino, Giolli, and Mele (2015) have tested Wagner's Law and the Keynesian hypothesis in 27 EU countries during the period 1980-2013. They have found that some European countries supported eitherWagner's Law or the Keynesian hypothesis. Besides, it has concluded that there is no unidirectional or bi-directional relationship between economic growth and public expenditures in 12 European countries.

When we review the literature on Wagner's Law, we see that there are many studies which have tested both Wagner's Law and the Keynesian hypothesis by using different econometric methods. Those studies have point out the direction of the causality, but have not point outthe value of the slope coefficients. The difference of our empirical study from the literature is to use an advanced econometric technique that is not used in previous empirical studies. With this method, we can determine both the value of the slope coefficient and the direction of the causality.

\section{The Data Set and the Model}

Our aim is to explore the causality relation between public expenditures and real GDP in 11 Southeastern European countries (Albania, Bosnia and Herzegovina, Bulgaria, Croatia, Greece, North Macedonia, Montenegro, Romania, Serbia, Slovenia, and Turkey) by using Kónya (2006) causality method. We have chosen a 16-year (from 2002 to 2017) depending on the availability of data. All data is taken from World Bank database as seen below.

Table 1. Definitions of Variables

\begin{tabular}{|c|l|l|}
\hline Variables & Explanation & Source \\
\hline RGDP & $\begin{array}{l}\text { Real Gross Domestic } \\
\text { Product (Dollar prices as } \\
\text { of 2010) }\end{array}$ & World Bank \\
\hline PE & $\begin{array}{l}\text { Total Public Expenditures } \\
\text { (Dollar prices) }\end{array}$ & World Bank \\
\hline
\end{tabular}

We have employed the model that is given below for testing Wagner's Law (Peacock and Wiseman, 1961):

$$
P E_{i, t}=\beta_{0}+\beta_{1} R G D P_{i, t}+u_{i, t}, \quad \beta_{1}>1
$$

In this model, $u_{i, t}$ denotes the residual term, $\beta_{1}$ denotes the coefficient for the real GDP (the slope coefficient). Peacock and Wiseman (1961) have considered 
The Relationship between Public Expenditures and Economic Growth in Southeastern European Countries: An Analysis of Bootstrap Panel Granger Causality

public expenditures as a logarithmic function of GDP. However, we do not need to use logarithms to determine the causality relationship between variables. We also do not need to search for the stationary of variables because this test allows us to use raw data. According to Wagner, the slope coefficient must be greater than 1 .

Keynes' equation can be denoted as the equation that is given below due to seeking bi-directional causality in this relation.

$R G D P_{i, t}=\alpha_{0}+\alpha_{1} P E_{i, t}+u_{i, t}$

\section{Methodology}

Granger causality refers that lags of one variable are used to estimate another variable. Two features should be provided to test the existence of Granger causality in panel data. The first feature is cross-sectional dependence that means if there is a cross-sectional dependence, any shock in one country conveys to another one. The second feature is slope heterogeneity. Heterogeneity in panel data means that each country are affected by their certain characteristics. According to Kónya (2006), both cross-sectional dependence and heterogeneity should be in panel data to test bootstrap panel Granger causality analysis. Therefore, before Kónya (2006) bootstrap panel Granger causality test is used by researchers, the presence of both assumptions (cross-sectional dependence and heterogeneity) should be checked.

There are some advantages of Kónya (2006) test. The first advantage is that the unit root and the cointegration tests are not required for the variables. For this reason, all variables are used in the level. The use of variables in other forms can cause the disappear of trend dynamics in panel time series.

The second advantage is that Kónya (2006) test accepts simultaneous correlation in panel (Mutascu, 2015, Zhang et al 2016).

Hence, two assumptions must be met for investigating the relation of panel causality that is developed by Kónya (2006):

i. Deciding if there are cross-sectional dependencies of variables in the data set. In the study, we have used the CD test of Breusch and Pagan (1980) and the $\mathrm{LM}_{\mathrm{adj}}$ test of Pesaran et.al (2008) because of the number of time dimension (16 years) is greater than the numbers of cross-section dimension of the data. There is also a CD test of Pesaran in addition to those tests.

LM test which is deveoped by Breusch and Pagan (1980) evaluates crosssectional dependencies. The equation in SUR system is required for estimating the model:

$y_{i t}=\alpha_{i}+\beta_{i}^{\prime} x_{i t}+u_{i t} ; i=1,2, \ldots, N ; t=1,2, \ldots, T$

DOI: $10.24818 / 18423264 / 54.3 .20 .15$ 
Hatice Altinok, Mehmet Oğuz Arslan

In Eq.(3), $x_{i t}$ denotes the vector of independent variables in form $k \times 1, \alpha_{i}$ ve $\beta_{i}^{\prime}$ denote the country-specific intercepts and the slope coefficients of countries respectively. The null hypothesis of LM test is nonexistence of cross-sectional dependence $\left(H_{0}=\operatorname{Cov}\left(u_{i t}, u_{j t}\right)=0, \forall t, i \neq j\right)$. An alternative hypothesis is the existence of cross-sectional dependence among error terms $\left(H_{1} \neq \operatorname{Cov}\left(u_{i t}, u_{j t}\right)=\right.$ $0, \exists t, i \neq j)$. The test statistics given below is used for testing null hypothesis:

$$
L M=T\left(\sum_{i=1}^{N-1} \sum_{j=i+1}^{N} \hat{\rho}_{i j}^{2}\right)
$$

$\hat{\rho}_{i j}^{2}$ denotes the correlation of residuals from a pooled OLS estimation of Eq. (4) for each country. The second test, CD test (Peseran, 2004) is applied if N > $\mathrm{T}$. The null hypothesis for $\mathrm{CD}$ test is nonexitence of cross-sectional dependence $(T \rightarrow \infty$ ve $N \rightarrow \infty)$ and demonstrated in Eq.(5):

$$
C D=\left(\frac{2 T}{N(N-1)}\right)^{1 / 2}\left(\sum_{i=1}^{N-1} \sum_{j=i+1}^{N} \hat{\rho}_{i j}\right)
$$

Pesaran, Ullah ve Yamagata (2008) adds the mean and the variance to LM test and developed a corrected version of LM test:

$$
L M_{a d j}=\left(\frac{2}{N(N-1)}\right)^{1 / 2}\left(\sum_{i=1}^{N-1} \sum_{j=i+1}^{N} \hat{\rho}_{i j} \frac{(T-k) \hat{\rho}_{i j}^{2}-\mu_{T i j}}{v_{T i j}}\right)
$$

$\mu_{T i j}$ ve $v_{T i j}$ in Eq.(6) denotes the mean and the standart deviation of $(T-k) \hat{\rho}_{i j}^{2}$ respectively (Pesaran et al., 2008).

Testing if the slope coefficient among panel countries distributed homogeneity or heterogeneity in panel countries. If $\mathrm{N}<\mathrm{T}$, Wald test is a proper method used for this aim. The null hypothesis for this test is that all coefficients are equal and the alternative ance of trend dynamics in panel time series.

ii. hypothesis is that at least one coefficient should be different from others. The test given in Eq.(7) is developed by Swamy (1970) for testing the heterogeneity amongst cuntries:

$$
\tilde{S}=\sum_{i=1}^{N}\left(\left(\widehat{\beta}_{\iota}-\widetilde{\beta_{W F E}}\right)\right)^{\prime} \frac{x_{i}^{\prime} M_{\tau} x_{i}}{\hat{\sigma}_{i}^{2}}\left(\widehat{\beta}_{\iota}-\widetilde{\beta_{W F E}}\right)
$$

In Eq.(7), $\widehat{\beta}_{l}$ denotes the estimator of pooled OLS, $\widehat{\beta_{W F E}}$ is a calculated value based on weighted fixed effect pooled estimator, $M_{\tau}$ is a defined matrix, $\hat{\sigma}_{i}^{2}$ is the estimator of $\sigma_{i}^{2}$. 
The Relationship between Public Expenditures and Economic Growth in Southeastern European Countries: An Analysis of Bootstrap Panel Granger Causality

Pesaran ve Yamagata (2008) have improved Swamy test as seen in Eq.(8) and Eq.(9)

$$
\begin{aligned}
\widetilde{\Delta}=\sqrt{N}\left(\frac{N^{-1} \tilde{S}-k}{\sqrt{2 k}}\right) & \\
\widetilde{\Delta}_{a d j} & =\sqrt{N}\left(\frac{N^{-1} \tilde{S}-E\left(\widetilde{z_{l t}}\right)}{\sqrt{\operatorname{var}\left(\widetilde{z_{l t}}\right)}}\right)
\end{aligned}
$$

In Eq. (8), $E\left(\widetilde{z_{l t}}\right)=k$ gives the mean, $\operatorname{var}\left(\widetilde{z_{l t}}\right)=2 k(T-k-1) /(T+1)$ gives the variance.

Because of both cross-sectional dependencies and the slope coefficients of countries are heterogeneous in our panel data set, we can apply to the panel Granger causality test of Kónya (2006). Kónya's (2006) test is based on seemingly unrelated regressions (SUR) system. This test is more efficient than OLS if there are dependencies between sections. The directions of causality are determined based on the country-specific critical values of bootstrap and Walt test in Kónya's (2006) test. Hence, this test does not form a common-joint hypothesis (Kónya, 2006).

Two equation sets are used for the panel Granger causality test of Kónya (2006):

$$
\begin{gathered}
R G D P_{1, t}=\alpha_{1,1}+\sum_{\substack{i=1 \\
m l R G D P_{1}}}^{m l R G D P_{1}} \lambda_{1,1, i} R G D P_{1, t-1}+\sum_{i=1}^{m l P E_{1}} \mu_{1,1, i} P E_{1, t-1}+\varepsilon_{1,1, t} \\
R G D P_{2, t}=\alpha_{1,2}+\sum_{i=1}^{m l P E_{1}} \lambda_{1,2, i} R G D P_{2, t-1}+\sum_{i=1}^{m} \mu_{1,2, i} P E_{2, t-1}+\varepsilon_{1,2, t}(10) \\
R G D P_{N, t}=\alpha_{1, N}+\sum_{i=1}^{m l R G D P_{1}} \lambda_{1, N, i} R G D P_{N, t-1}+\sum_{i=1}^{m l P E_{1}} \mu_{1, N, i} P E_{N, t-1}+\varepsilon_{1, N, t}
\end{gathered}
$$
and

$$
\begin{array}{r}
P E_{1, t}=\alpha_{2,1}+\sum_{i=1}^{m l R G D P_{2}} \lambda_{2,1, i} R G D P_{1, t-1}+\sum_{i=1}^{m l P E_{2}} \mu_{2,1, i} P E_{1, t-1}+\varepsilon_{2,1, t} \\
P E_{2, t}=\alpha_{2,2}+\sum_{i=1}^{m l R G D P_{2}} \lambda_{2,2, i} R G D P_{2, t-1}+\sum_{i=1}^{m l C P E_{2}} \mu_{2,2, i} P E_{2, t-1}+\varepsilon_{2,2, t}
\end{array}
$$

DOI: 10.24818/18423264/54.3.20.15 
Hatice Altinok, Mehmet Oğuz Arslan

$$
P E_{2, t}=\alpha_{2, N}+\sum_{i=1}^{m l R G D P_{2}} \lambda_{2, N, i} R G D P_{N, t-1}+\sum_{i=1}^{m l P E_{2}} \mu_{2, N, i} P E_{N, t-1}+\varepsilon_{2, N, t}
$$

$N$ indicates the number of countries $(\mathrm{i}=1,2, \ldots, 11), t$ indicates period $(2002$, $2003, \ldots, 2007)$, and $l$ indicates the length of lag in sets of Eq.(10) and Eq.(11). It is expected that $\varepsilon_{1, N, t}$ and $\varepsilon_{2, N, t}$ establish a simultaneous relationship on equations depending on joint random shocks. Moreover, the model provides a deterministic trend. $\alpha, \mu$, and $\lambda$ coefficients denote the slope coefficients in Eq.(10) and Eq.(11). In all equation systems, there are the number og maximum lags for PE and RGDP.

Equation systems of (10) and (11) let us do one-directional and bi-directional Granger causality test for each country. If all $\mu_{1, N, i}$ in equation set of (10) are not equal to zero but all $\lambda_{2, N, i}$ in equation set of (11) are equal to zero, there is onedirectional causality from public expenditures to GDP for each country. Contrarily, If all $\mu_{1, N, i}$ in equation set of (10) are equal to zero but all $\lambda_{2, N, i}$ in equation set of (11) are not equal to zero, there is one-directional causality from GDP to public expenditures for each country. Neither all $\mu_{1, N, i}$ nor all $\lambda_{2, N, i}$ should be equal to zero to have a bi-directional causality between GDP and public expenditures. If all $\lambda_{2, N, i}$ and $\mu_{1, N, i}$ are equal to zero, it implies that there is no causality between GDP and public expenditures (Kónya, 2006).

\section{Empirical Results}

Our empirical study begins with testing the existence of two assumptions in the panel bootstrap Granger causality test. As previously stated in Kónya (2006), the first assumption in the causality test examines the existence of cross-sectional dependence. Since the time dimension $(\mathrm{T}=16)$ is larger than the section unit $(\mathrm{N}=11)$ in the panel, we can use three different tests (LM test, CD test, and $\mathrm{LM}_{\text {adj }}$ ) to investigate the existence of cross-sectional dependence. The second assumption determines homogeneity or heterogeneity of the slope coefficient in the causality test for countries in the panel. We carry out two different delta tests $(\tilde{\Delta}$ test and $\tilde{\Delta}_{\text {adj }}$ test) which are taken from Pesaran ve Yamagata (2008).

The results of tests for cross-sectional dependence and slope homogeneity are presented in Table 2 for equation (1). The first set of results that the null hypothesis is no cross-sectional dependence is rejected regarding three tests. This means that in the Southeastern European countries there is a cross-sectional dependence, therefore any shock in one country conveys to another one. The second set of results that the null hypothesis of slope homogeneity test is rejected by both $\tilde{\Delta}$ test and $\tilde{\Delta}_{a d j}$ test. Therefore, the results of the slope homogeneity test support the alternative hypothesis that asserts heterogeneity is strongly existing among 
The Relationship between Public Expenditures and Economic Growth in Southeastern European Countries: An Analysis of Bootstrap Panel Granger Causality

Southeastern European countries. This case is important because each country is affected by their certain characteristics. The causality relationship between public expenditures and economic growth is different for each country.

Table 2.Cross-sectional dependence and slope homogeneity test results

\begin{tabular}{|c|c|c|}
\hline Method & Test statistics & p-value \\
\hline \multicolumn{3}{|c|}{ Cross-sectional dependence tests $\left(P E_{i, t}=\beta_{0}+\beta_{1} R G D P_{i, t}+u_{i, t}\right)$} \\
\hline LM test & $652.8349^{* *}$ & 0.0000 \\
\hline CD test & $55.95251^{* *}$ & 0.0000 \\
\hline $\mathrm{LM}_{\text {adj }}$ test & $25.43782^{* *}$ & 0.0000 \\
\hline \multicolumn{3}{|c|}{ Slope homogeneity tests } \\
\hline$\tilde{\Delta}$ test & $5.346^{* *}$ & 0.000 \\
\hline$\tilde{\Delta}_{a d j}$ test & $5.891^{\text {** }}$ & 0.000 \\
\hline \multicolumn{3}{|c|}{$\begin{array}{l}\text { Notes: } \\
\text { (1) } *, * * \text { and } * * * \text { are significant at } 0.1,0.05 \text { and } 0.01 \text { significance levels } \\
\text { respectively. } \\
\text { (2) LM test, LMadj test, and CD test represent the cross-sectional } \\
\text { dependence tests of Breusch and Pagan (1980), Pesaran (2004) and } \\
\text { Pesaran et al. }(2008) \text {. } \\
\text { (3) } \tilde{\Delta} \text { and } \tilde{\Delta}_{\text {adj }} \text { tests denote the slope homogeneity tests proposed by } \\
\text { Pesaran and Yamagata (2008). }\end{array}$} \\
\hline
\end{tabular}

The results of tests for cross-sectional dependence and slope homogeneity are presented in Table 3 for equation (2). As seen in Table 3, the first set of results show that the null hypothesis is rejected by three tests. The second set of results shows that the null hypothesis of the slope homogeneity test is rejected by both $\tilde{\Delta}$ test and $\tilde{\Delta}_{a d j}$ test. Therefore, the results of the cross-sectional dependence test and slope homogeneity test support the alternative hypothesis which asserts crosssectional dependence and heterogeneity is strongly existing.

DOI: 10.24818/18423264/54.3.20.15 
Hatice Altinok, Mehmet Oğuz Arslan

Table 3.Cross-sectional dependence and slope homogeneity test results

\begin{tabular}{|c|c|c|}
\hline Method & Test statistics & $\mathrm{p}$-value \\
\hline \multicolumn{3}{|c|}{ Cross-sectional dependence tests $\left(R G D P_{i, t}=\alpha_{0}+\alpha_{1} P E_{i, t}+u_{i, t}\right)$} \\
\hline LM test & $632.5806^{* *}$ & 0.0000 \\
\hline CD test & $24.99223^{* *}$ & 0.0000 \\
\hline $\mathrm{LM}_{\text {adj }}$ test & $54.02134^{* *}$ & 0.0000 \\
\hline \multicolumn{3}{|c|}{ Slope homogeneity tests } \\
\hline$\tilde{\Delta}$ test & $3.898 * *$ & 0.000 \\
\hline$\tilde{\Delta}_{a d j}$ test & $4.296^{* *}$ & 0.000 \\
\hline \multicolumn{3}{|c|}{$\begin{array}{l}\text { Notes: } \\
\text { (1) } *, * * \text { and } * * * \text { are significant at } 0.1,0.05 \text { and } 0.01 \text { significance levels } \\
\text { respectively. } \\
\text { (2) } L M \text { test, LMadj test, and CD test represent the cross-sectional } \\
\text { dependence tests of Breusch and Pagan (1980), Pesaran (2004) and } \\
\text { Pesaran et al.(2008). } \\
\text { (3) } \tilde{\Delta} \text { and } \tilde{\Delta}_{\text {adj }} \text { tests denote the slope homogeneity tests proposed by } \\
\text { Pesaran and Yamagata (2008). }\end{array}$} \\
\hline
\end{tabular}

Because of that, the assumptions of both cross-sectional dependence and slope heterogeneity are validated for either equation (1) and equation (2), the Kónya (2006) bootstrap Granger causality test can be used to determine the direction of relationships between variables and the slope coefficients. The results of Konya (2006) bootstrap causality test are presented in Table 4.

Table 4.The Kónya bootstrap panel Granger causality results
$\mathrm{H}_{0}: \mathrm{RGDP} \nrightarrow \mathrm{PE}$
$\mathrm{H}_{0}: \mathrm{PE} \nrightarrow \mathrm{RGDP}$
$\mathrm{H}_{1}: \mathrm{RGDP} \rightarrow \mathrm{PE}$
$\mathrm{H}_{1}: \mathrm{PE} \rightarrow \mathrm{RGDP}$ 
The Relationship between Public Expenditures and Economic Growth in Southeastern European Countries: An Analysis of Bootstrap Panel Granger Causality

\begin{tabular}{|c|c|c|c|c|}
\hline Countries & $\begin{array}{l}\text { Wald test } \\
\text { (p-value) }\end{array}$ & $\begin{array}{l}\text { Coefficient } \\
\text { value }\end{array}$ & $\begin{array}{l}\text { Wald test } \\
\text { (p-value) }\end{array}$ & $\begin{array}{l}\text { Coefficientva } \\
\text { lue }\end{array}$ \\
\hline Albania & $\begin{array}{l}26.239771 \\
(0.00000)\end{array}$ & $0.434072 * *$ & $\begin{array}{l}12.694772 \\
(0.00037)\end{array}$ & $-0.044745^{* *}$ \\
\hline $\begin{array}{l}\text { BosniaandHer } \\
\text { zegovina }\end{array}$ & $\begin{array}{l}4.5890614 \\
(0.03218)\end{array}$ & $0.177857 * *$ & $\begin{array}{l}19.418466 \\
(0.00001)\end{array}$ & $-0.206129 * *$ \\
\hline Bulgaria & $\begin{array}{l}1.0424595 \\
(0.30725)\end{array}$ & 0.072767 & $\begin{array}{l}6.5161113 \\
(0.01069)\end{array}$ & $0.630932 * *$ \\
\hline Croatia & $\begin{array}{l}34.149683 \\
(0.00000)\end{array}$ & $0.516649 * *$ & $\begin{array}{l}3.8574776 \\
(0.04952)\end{array}$ & $-0.167889 * *$ \\
\hline Greece & $\begin{array}{l}44.572049 \\
(0.0000)\end{array}$ & $0.404453^{* *}$ & $\begin{array}{l}69.859948 \\
(0.00000)\end{array}$ & $-0.427517 * *$ \\
\hline $\begin{array}{l}\text { North } \\
\text { Macedonia }\end{array}$ & $\begin{array}{l}24.671041 \\
(0.0000)\end{array}$ & $0.227742 * *$ & $\begin{array}{l}0.72865862 \mathrm{E}-02 \\
(0.93197)\end{array}$ & $\begin{array}{l}0.593682 \mathrm{E}- \\
02\end{array}$ \\
\hline Montenegro & $\begin{array}{l}61.048678 \\
(0.00000)\end{array}$ & $0.823105 * *$ & $\begin{array}{l}41.562456 \\
(0.0000)\end{array}$ & $-0.370225^{* *}$ \\
\hline Romania & $\begin{array}{l}11.316416 \\
(0.00077)\end{array}$ & $0.269863^{* *}$ & $\begin{array}{l}32.784098 \\
(0.00000)\end{array}$ & $-0.453753^{* *}$ \\
\hline Serbia & $\begin{array}{l}12.481194 \\
(0.00041)\end{array}$ & $0.447252 * *$ & $\begin{array}{l}4.0496532 \\
(0.04418)\end{array}$ & $-0.132126^{* *}$ \\
\hline Slovenia & $\begin{array}{l}6.5164422 \\
(0.01069)\end{array}$ & $0.135834 * *$ & $\begin{array}{l}5.3247638 \\
(0.02102)\end{array}$ & $0.458643^{* *}$ \\
\hline Turkey & $\begin{array}{l}0.55051885 \mathrm{E} \\
-02 \\
(0.94085)\end{array}$ & $\begin{array}{l}-.255237 \mathrm{E}- \\
02\end{array}$ & $\begin{array}{l}4.2016039 \\
(0.04039)\end{array}$ & $-0.264325^{* *}$ \\
\hline
\end{tabular}

By means of the Kónyatest, Table 4 shows that we can interpret this study in two different ways. Because Kónyatest gives us both the results of the Wald test and the coefficient value of the model for interpreting the direction of the causality and the slope coefficient, respectively. The first one is that Granger causality from RGDP to public expenditures exists for nine countries (Albania, Bosnia Herzegovina, Croatia, Greece, North Macedonia, Montenegro, Romania, Serbia, and Slovenia) according to Wald test. Also, the null hypothesis (RGDP $\rightarrow$ GE) can not be rejected for Bulgaria and Turkey. As seen in Eq.(1), the slope coefficient should be greater than 1 in Wagner's Law.

DOI: $10.24818 / 18423264 / 54.3 .20 .15$ 
Hatice Altinok, Mehmet Oğuz Arslan

However, the second results show that Wagner's Law is not valid in these countries as for the slope coefficients of each country are smaller than 1, according to Kónya (2006)test. Unlike other econometric methods that measuring the causality, Kónya (2006) test gives us the slope coefficients for each country.

Table 4 also reveals that Granger causality from public expenditures to RGDP is found for 10 countries. As for North Macedonia, the null hypothesis can be accepted. Therefore, the estimation results put out the validity of the Keynesian hypothesis in these countries except North Macedonia.

As both Table 3 and Table 4, there is only a unidirectional causality from RGDP to public expenditures in North Macedonia. Yet, the opposite unidirectional causality from public expenditures to RGDP is valid only for Bulgaria and Turkey. In Albania, Bosnia and Herzegovina, Croatia, Greece, Montenegro, Romania, Serbia, and Slovenia, there is a bi-directional relationship between RGDP and public expenditures. Therefore, whereas Wagner's Law is only valid for Bulgaria, the Keynesian hypothesis is only valid for Turkey. Estimation results show the existence of both Wagner's Law and the Keynesian hypothesis for Albania, Bosnia Herzegovina, Croatia, Greece, Montenegro, Romania, Serbia, and Slovenia.

\section{Conclusion}

As one of the famous approaches in economics, Wagner's Law accepts economic growth as the main reason for an increase in public expenditures. In this study, we test the validity of Wagner's Law for the economies of Albania, Bosnia and Herzegovina, Bulgaria, Croatia, Greece, North Macedonia, Montenegro, Romania, Serbia, Slovenia, and Turkey by using Kónya (2006) bootstrap causality test that is not used in previous empirical studies. Unlike other causality tests in literature, Kónya (2006) bootstrap causality test has some advantages: (a) we can determine the direction of the causality relationship between variables by using the Wald test in the model. (b) we can also determine the coefficient of the independent variable (the slope coefficient) in the model. As far as we know, this study is the first study on Wagner's Law that use Kónya (2006) bootstrap causality test.

Table 5.The Directions of Causality in Southeastern European Countries (According to Wald Test)

\begin{tabular}{|c|c|c|}
\hline Hypothesis & Causality flow & Countries \\
\hline Bidirectional & $\mathrm{RGDP} \leftrightarrow \mathrm{PE}$ & $\begin{array}{lr}\text { Albania, Bosnia and } & \text { and } \\
\text { Herzegovina, } & \text { Croatia, } \\
\text { Greece, } & \text { Montenegro, } \\
\text { Romania, } & \text { Serbia, } \\
\text { Slovenia } & \end{array}$ \\
\hline
\end{tabular}


The Relationship between Public Expenditures and Economic Growth in Southeastern European Countries: An Analysis of Bootstrap Panel Granger Causality

\begin{tabular}{|c|c|c|}
\hline Wagner's law & $\mathrm{RGDP} \rightarrow \mathrm{PE}$ & North Macedonia \\
\hline Keynes' hypothesis & $\mathrm{PE} \rightarrow \mathrm{RGDP}$ & Turkey, Bulgaria \\
\hline Neutrality & - & - \\
\hline
\end{tabular}

As seen in Table 5, Granger causality from RGDP to public expenditures exists for nine countries (Albania, Bosnia Herzegovina, Croatia, Greece, North Macedonia, Montenegro, Romania, Serbia, and Slovenia) according to Wald test. Wagner's Law is rejected for Bulgaria and Turkey.The results also reveal that there is Granger causality from public expenditures to RGDP in 10 countries. As for North Macedonia, Keynes' hypothesis is rejected. According to the study, Wagner's Law is valid in 8 of 11 Southeastern European countries. However, the result of the study changes as for Kónya (2006) test. Wagner's Law is not found valid forall Southeastern European countriesbecause, the slope coefficients ofthose countries are smaller than 1, according to Kónya (2006) test.

\section{REFERENCES}

[1] Afonso, A., Alves, J. (2016), Reconsidering Wagner's Law: Evidence from the Functions of the Government. Lisbon School of Economics and Management Working Paper, WP09/2016/DE/UECE;

[2] Breusch, T. S.,Pagan, A. R. (1980),The Lagrange Multiplier Test and its Applications to Model Specification in Econometrics. The Review of Economic Studies, 47(1):239-253;

[3] Chletsos, M., Kollias, C. (1997),Testing Wagner's Law Using

Disaggregated Public Expenditure Data in the case of Greece: 1958-93. Applied Economic, 29(3): 371-377;

[4] Dritsakis, N., Adamopoulos, A. (2004), A Causal Relationship between Government Spending and Economic Development: an Empirical Examination of the Greek Economy. Applied Economics, 36(5):457-464;

[5] Guseh, J. S. (1997),Government Size and Economic Growth in Developing

Countries: a Political-Economy Framework. Journal of Macroeconomics, 19(1): 175-192;

[6] Halıcıoğlu, F. (2003), Testing Wagner's Law for Turkey, 1960-2000. Review of Middle East Economics and Finance, 1(2):129-141;

[7] Jaen-Garcia, M. (2011),Empirical Analysis of Wagner's Law for the Spain's Regions. International Journal of Academic Research in Accounting, Finance and Management Sciences, 1(1):1-17;

[8] Islam, A. M. (2001),Wagner's Law Revisited: Cointegration and Exogeneity Tests for the USA. Applied Economics Letters, 8:509-515;

DOI: $10.24818 / 18423264 / 54.3 .20 .15$ 
Hatice Altinok, Mehmet Oğuz Arslan

[9] Kuckuck, J. (2012), Testing Wagner's Law at Different Stages of Economic Development a Historical Analysis of Five Western European Countries.

Working Paper 91;

[10] Kónya, L. (2006), Exports and Growth: Granger Causality Analysis on OECD Countries with a Panel Data Approach. Economic Modelling, 23(6): 978-992. doi: 10.1016/j.econmod.2006.04.008;

[11] Magazzino, C. (2010),Wagner's Law and Augmented Wagner's Law in EU-27. A Time-Series Analysis on Stationarity, Cointegration and Causality. MPRA Papers No. 26668;

[12] Magazzino, C., Giolli, L., Mele, M. (2015),Wagner's Law and Peacock and Wiseman's Displacement Effect in European Union Countries: a Panel Data Study. International Journal of Economics and Financial Issues, 5(3):812819;

[13] Mann, A. J. (1980),Wagner's Law: an Econometric Test for Mexico, 1925-1976. National Tax Journal, 33(2):189-201;

[14] Mutascu, M. (2015),A Bootstrap Panel Granger Causality of Energy Consumption and Economic Growth in the G7 Countries. Renewable and Sustainable Energy Reviews, 63:166-171;

[15] Narayan, P. K., Nielsen, I., Smyth, R. (2008),Panel Data, Cointegration, Causality and Wagner's Law: Empirical Evidence from Chinese Provinces. China Economic Review, 19:297-307;

[16] Peacock, A., J. Wiseman, (1961), The Growth of Public Expenditure in the United Kingdom. Londra:George Allen and Unwin;

[17] Pesaran, M. H. (2004), General Diagnostic Tests for Cross Section Dependence in Panels. Cambridge: Faculty of Economics, University of Cambridge. Cambridge Working Papers in Economics No: 0435;

[18] Pesaran, M. H., Yamagata, T. (2008),Testing Slope Homogeneity in Large Panels. Econometrics, 142:50-93;

[19]Pesaran, M. H., Ullah, A., Yamagata, T. (2008),A Bias-adjusted LM Test of Error Cross-section Independence. Econometrics Journal, 11,105-127; [20] Swamy, P. A. V. B. (1970), Efficient Inference in a Random Coefficient Regression Model. Econometrica, 38(2):311-323;

[21] Tanninen, H. (1999),Income Inequality, Government Expenditures and Growth.Applied Economics, 31(9):1109-117;

[22] Wagner, A. (1883),Three Extracts on Public Finance, Musgrave, A.R., Peacock, A.T., (ed.) (1967), Classics in the Theory of Public Finance,1-27;

[23] Zhang, X., Chang, T., Su C. W., Wolde-Rufael, Y. (2016),Revisit Causal nexus between Military Spending and Debt: a Panel Causality Test. Economic Modelling, 52:939-944;

[24] https://data.worldbank.org. 